\title{
Aspirin resistance in the era of personalized medicine: Should we not take it personally?
}

\author{
Phillip S. Naimo, MD, ${ }^{\text {a,b,c }}$ David McGiffin, MD, FRACS, ${ }^{\text {d }}$ and Igor E. Konstantinov, MD, PhD, FRACS ${ }^{\mathrm{a}, \mathrm{b}, \mathrm{c}}$
}

\footnotetext{
From the ${ }^{a}$ Department of Cardiothoracic Surgery, Royal Children's Hospital, Melbourne, Australia; ${ }^{b}$ Murdoch Children's Research Institute, Melbourne, Australia; the ${ }^{c}$ University of Melbourne, Melbourne, Australia; and the ${ }^{\mathrm{d}}$ Department of Cardiothoracic Surgery, The Alfred Hospital, Melbourne, Australia.

Disclosures: Authors have nothing to disclose with regard to commercial support.

Received for publication Sept 6, 2015; accepted for publication Sept 8, 2015; available ahead of print Oct 10, 2015.

Address for reprints: Igor E. Konstantinov, MD, PhD, FRACS, Royal Children's Hospital, Flemington Rd, Parkville, Victoria 3029, Australia (E-mail: igor.konstantinov@rch.org.au).

J Thorac Cardiovasc Surg 2015;150:e99-100

$0022-5223 / \$ 36.00$

Crown Copyright $@ 2015$ Published by Elsevier Inc. on behalf of The American Association for Thoracic Surgery http://dx.doi.org/10.1016/j.jtcvs.2015.09.049
}

An interesting and thought-provoking article by DeNino and colleagues ${ }^{1}$ appears in the current issue of the Journal. This article describes 2 patients with HeartMate II (Thoratec Corporation, Pleasanton, Calif) left ventricular assist device (LVAD) in whom pump thrombosis developed despite what appeared to be an appropriate initial anticoagulation regimen. Both initially received aspirin at low dose (81 mg daily), heparin, and warfarin. The initial responsiveness to aspirin, defined as less than 550 aspirin reaction units (ARU), was confirmed in both patients. Both became unresponsive to aspirin. Both appeared noncompliant with their anticoagulation regimens. Did both have aspirin resistance, or resistance to taking aspirin? How can one determine the causes of diverse prothrombotic conditions that are pulled together and called "aspirin resistance"? What is this elusive aspirin resistance anyway? The article by DeNino and colleagues ${ }^{1}$ poses more questions than it gives answers. Yet one has to begin somewhere, and this article is an excellent beginning. It does not provide the solution, but rather it brings attention to a complex problem yet to be solved.

As we enter the era of personalized medicine, a few comments on aspirin resistance and its relevance to cardiac surgeons appear timely. Aspirin resistance is a real phenomenon and defined as the inability of aspirin to reduce platelet production of thromboxane $\mathrm{A}_{2}\left(\mathrm{TXA}_{2}\right.$; Figure 1) and thereby platelet activation and aggregation. ${ }^{2}$ Aspirin is a nonselective and irreversible inhibitor of both forms of cyclooxygenase (COX), but is weakly more selective for COX-1. Aspirin inhibition of COX-1 is rapid and saturable at low doses. This may leave some COX-2, which is greatly upregulated by proinflammatory conditions, uninhibited. Thus $\mathrm{TXA}_{2}$ can be produced by activated macrophages, monocytes, and endothelial cells through COX-2. Interestingly, higher doses of aspirin cause greater inhibition of COX-2 and dramatically lower concentration of urinary 11-dehydrothromboxane $\mathrm{B}_{2} \cdot{ }^{3,4}$ The Heart Outcomes

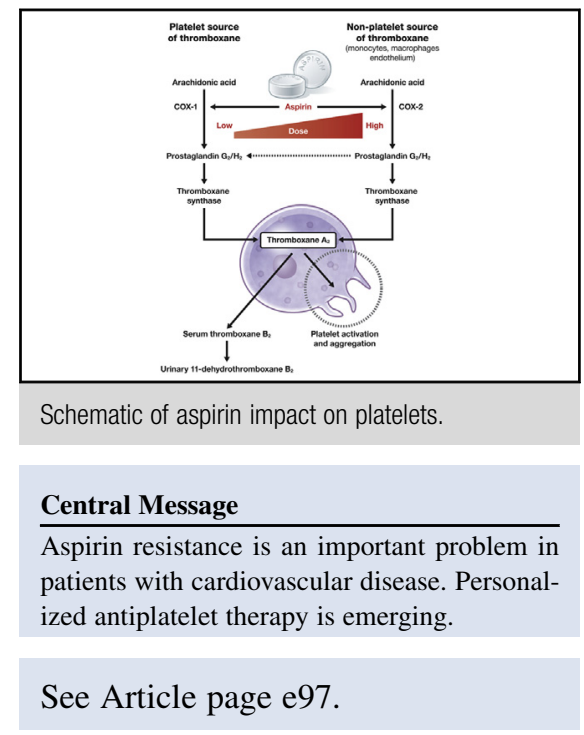

Prevention Evaluation study ${ }^{5}$ demonstrated that patients in the highest quartile of urinary-11-dehydrothromboxane $\mathrm{B}_{2}$ levels had significantly higher risk of myocardial infarction, stroke, or cardiovascular death compared with patients in the lower quartile.

Laboratory diagnosis of aspirin resistance can be established by measuring platelet $\mathrm{TXA}_{2}$ production or $\mathrm{TXA}_{2}$-dependent platelet function. The light or optical transmittance aggregometry has been the criterion standard, yet it is time consuming and clinically impractical. The VerifyNow Rapid Platelet Function Test (Accumetrics, Accriva Diagnostics, San Diego, Calif) has demonstrated excellent correlation with optical aggregometry and the rate of cardiovascular events. ${ }^{6}$ It allows rapid bedside analysis of blood and monitoring of not only aspirin but also other antiplatelet agents, including thienopyridines and IIB/IIIA inhibitors. The test is performed in a sample of whole blood by adding an agonist, arachidonic acid, to measure platelet aggregation to fibrinogen-coated beads. Platelet aggregation increases light transmittance, which is recorded as ARU. Values of 550 ARU or higher indicate persistent aggregation and thus unresponsiveness. The test requires $2 \mathrm{~mL}$ of blood and has also been used in children, including neonates, after cardiac surgery.

It would certainly be helpful to determine aspirin resistance before the clinical thrombotic event occurred. Once aspirin resistance has been determined, what should we do about it? Simple increase of aspirin dose can be sufficient in some patients but detrimental in others. Ideally, 


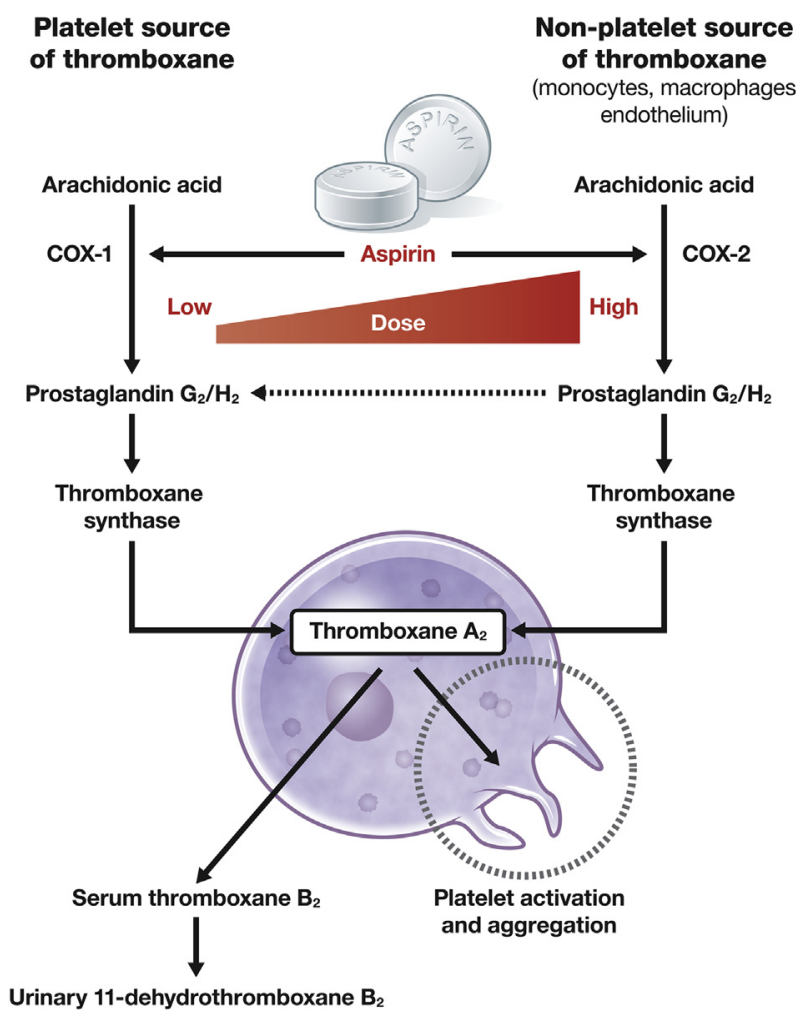

FIGURE 1. Schematic impact of low-dose aspirin on platelet activation and aggregation. Aspirin in low doses may leave some COX-2, production of which may significantly increase in inflammatory conditions, uninhibited, and result in increased platelet activation and aggregation. $\mathrm{COX}, \mathrm{Cy}-$ clooxygenase.

the cause of aspirin resistance should be identified to guide an individualized antiplatelet therapy. The causes of aspirin resistance, however, are numerous. ${ }^{1,6}$ As many as $40 \%$ of patients with cardiovascular disease are noncompliant with aspirin therapy. ${ }^{1,8}$ Other major causes of aspirin resistance include drug interaction, hyperglycemia, increased serum catecholamine level, tachyphylaxis with prolonged administration, and, in as many as $30 \%$ of patients, genetic polymorphism. ${ }^{2,9}$ Aspirin resistance in anticoagulated patients becomes more complex because of variable genotype polymorphism for both antiplatelet and anticoagulation agents. ${ }^{10}$ After all, a simple flu can activate platelets $^{11}$ and change the response to aspirin. Is it possible to individualize antiplatelet and anticoagulation therapy in our surgical patients?
The cost of sequencing the human genome has fallen so dramatically during the last decade ${ }^{12}$ that within a few years clinically affordable sequencing can be done in every patient. An individualized "aspirin response genomic signature" is being identified. ${ }^{13,14}$ The time of personalized antiplatelet and anticoagulation therapy is coming fast. ${ }^{15}$ We had better be ready for it.

Early identification and stratification of nonresponders as well as personalized therapy would bring dramatic benefits not only to patients requiring anticoagulation for LVADs or mechanical heart valves but also to millions of people taking aspirin.

\section{References}

1. DeNino WF, Floroff C, Uber WE, Ikonomidis JS. Aspirin resistance: a role in left ventricular assist device thrombosis? J Thorac Cardiovasc Surg. 2015;150: e97-8.

2. Hankey GJ, Eikelboom JW. Aspirin resistance. Lancet. 2006;367:606-17.

3. FitzGerald GA, Oates JA, Hawiger J, Maas RL, Roberts LJ II, Lawson JA, et al. Endogenous biosynthesis of prostacycline and thromboxane and platelet function during chronic administration of aspirin in man. J Clin Invest. 1983; 71:676-88

4. Hart RG, Leonard AD, Talbert RL, Pearce LA, Cornell E, Bovill E, et al. Aspirin dosage and thromboxane synthesis in patients with vascular disease. Pharmacotherapy. 2003;23:579-84.

5. Eikelboom JW, Hirsh J, Weitz JI, Johnston M, Yi Q, Yusuf S. Aspirin-resistant thromboxane biosynthesis and the risk of myocardial infarction, stroke, or cardiovascular death in patients at high risk for cardiovascular events. Circulation. 2002; 105:1650-5.

6. Wang JC, Aucoin-Barry D, Manuelian D, Monbouquette R, Reisman M, Gray W, et al. Incidence of aspirin nonresponsiveness using the Ultegra Rapid Platelet Function Assay-ASA. Am J Cardiol. 2003;92:1492-4.

7. Emani S, Trainor B, Zurakowski D, Baird CW, Fynn-Thompson FE, Pigula FA, et al. Aspirin unresponsiveness predicts thrombosis in high-risk pediatric patients after cardiac surgery. J Thorac Cardiovasc Surg. 2014;148:840-4; discussion 814-6.

8. Schwartz KA, Schwartz DE, Ghosheh K, Reeves MJ, Barber K, DeFranco A. Compliance as a critical consideration in patients who appear to be resistant to aspirin after healing of myocardial infarction. Am J Cardiol. 2005;95:973-5.

9. Cambria-Kiely JA, Gandhi PJ. Aspirin resistance and genetic polymorphisms. J Thromb Thrombolysis. 2002;14:51-8.

10. Awad M, Czer LS, Soliman C, Mirocha J, Ruzza A, Pinzas J, et al. Prevalence of warfarin genotype polymorphisms in patients with mechanical circulatory support. ASAIO J. 2015;61:391-6.

11. Rondina MT, Brewster B, Grissom CK, Zimmerman GA, Kastendieck DH, Harris ES, et al. In vivo platelet activation in critically ill patients with primary 2009 influenza A (H1N1). Chest. 2012;141:1490-5.

12. Hayden EC. Technology: the $\$ 1,000$ genome. Nature. 2014;507:294-5.

13. Voora D, Cyr D, Lucas J, Chi JT, Dungan J, McCaffrey TA, et al. Aspirin exposure reveals novel genes associated with platelet function and cardiovascular events. J Am Coll Cardiol. 2013;62:1267-76.

14. Rose JJ, Voora D, Cyr DD, Lucas JE, Zaas AK, Woods CW, et al. Gene expression profiles link respiratory viral infection, platelet response to aspirin, and acute myocardial infarction. PLoS One. 2015;10:e0132259.

15. Beitelshees AL, Vora D, Lewis JP. Personalized antiplatelet and anticoagulation therapy: applications and significance of pharmacogenomics. Pharmgenomics Pers Med. 2015;8:43-61. 